\title{
Wild boar rooting intensity determines shifts in understorey composition and functional traits
}

\author{
S. Burrascano ${ }^{1,5}$, R. Copiz¹, E. Del Vicoํㅗ S. Fagiani², E. Giarrizzo ${ }^{1}$, M. Mei²,
}

\author{
A. Mortelliti2,3, F. M. Sabatini ${ }^{1,4}$ and C. Blasi ${ }^{1}$ \\ ${ }_{1}^{1}$ Department of Environmental Biology, Sapienza University of Rome, P.le Aldo Moro 5, 00185 Rome, Italy. \\ 2 Department of Biology and Biotechnology "Charles Darwin", Sapienza University of Rome, \\ Viale dell'Università 32, 00185 Rome, Italy \\ ${ }_{3}^{3}$ Department of Wildlife, Fisheries, and Conservation Biology, University of Maine, 5755 Nutting Hall, Orono, \\ ME 04469, U.S.A. \\ 4 Geography Department, Humboldt University, Unter den Linden 6, 10099 Berlin, Germany \\ ${ }_{5}^{5}$ Corresponding author. Fax: +390649912420; www.dba302.uniroma1.it, E-mail: sabinaburrascano@uniroma1.it
}

Keywords: Circeo National Park, Deciduous oak forest, Fourth-corner analysis, Indicator Species Analysis, Ruscus aculeatus, Sus scrofa.

\begin{abstract}
In recent decades, the European populations of wild boar have grown substantially, as has the impact of this species, owing above all to its rooting activity. Our aim was to investigate the relationships between vascular plant understorey and wild boar rooting intensity. The questions we addressed are: does rooting intensity influence understorey species composition and diversity? Which functional traits are associated with different levels of rooting? We performed a comparative analysis of plant communities in areas with contrasting levels of rooting intensity within a Mediterranean deciduous lowland forest in central Italy. Besides comparing species composition and diversity, we tested the association between species traits and rooting levels through fourth-corner analysis. We found that contrasting levels of rooting were associated to different understorey species composition and evenness, while we observed no significant difference in species richness. In contrast with our expectations, sites with lower rooting returned i) lower evenness values and ii) a higher proportion of species characterized by traits related to resistance or response to herbivory, i.e., spinescence, clonality, endozoochory, underground storage organs, and low height values. Our findings suggest that current vegetation patterns partly depend on the legacy effect of past rooting disturbance, since the areas currently subjected to low rooting intensity were likely to be intensely rooted in the past. These areas may have developed a marked dominance of clonal thorny species that, in turn, inhibited further feeding activities by wild boar.
\end{abstract}

Nomenclature for plants: Conti et al. (2005).

\section{Introduction}

European populations of wild boar (Sus scrofa L.) have grown substantially in recent decades (Saezroyuela and Telleria 1986, Wirthner et al. 2012) owing both to the ability of this species to adapt to different environments (Schley et al. 2008), and to a combination of reintroduction for hunting purposes (Champagnon et al. 2012), increasing tree mast frequency (Bieber and Ruf 2005), insufficient hunting pressure, and lack of predators (Barrios-Garcia and Ballari 2012). Wild boar activities impact crops, pastures and forests (BarriosGarcia and Ballari 2012) and cause direct economic damage by reducing agricultural incomes and transmitting diseases to humans and livestock (Barrios-Garcia and Ballari 2012). Although wild boar is a natural component of forest ecosystems, when the population is over-abundant it may have a profound impact on several ecosystem components since the effects of large herbivores are positively related to their den- sity, often in a nonlinear way (Nuttle et al. 2014). Such impact acts through several mechanisms ranging from the modification of habitat structure to the alteration of disturbance regime and food webs (Valenzuela et al. 2014).

Wild boar impact is often mediated by its rooting activity, i.e., the excavation of the surface soil layers in the course of foraging for food, which creates localized disturbance that appears similar to mechanical ploughing (Sims et al. 2014). Rooting may affect some key ecosystem components such as soil, overstorey regeneration and the herb-layer, in areas that range from a few square decimetres to hundreds of hectares (Welander 2000, Li et al. 2013).

In temperate forests, the ecosystem component most suitable for the study of the impact by wild boar is the understorey vegetation since it makes up most of the wild boar diet (Pinna et al. 2007, Cuevas et al. 2010, Sandom et al. 2013). Such a direct impact on understorey vegetation is of particular concern, since the herb-layer may account for up to $80 \%$ of plant 
species in forests, i.e., an important share of forest overall biological diversity (Gilliam 2007, Abbate et al. 2015).

Despite the relevance of wild boar-understorey interactions, most studies on the effects of this ungulate in forest systems focus on its effect on tree regeneration (Ickes et al. 2005, Gomez and Hodar 2008, Siemann et al. 2009). Therefore, a general consensus still lacks on the effects of rooting on understorey species richness and composition (Massei and Genov 2004). The impact on understorey vegetation depends both on direct and indirect mechanisms: direct effects include feeding on seeds, or on bulbs, corms and rhizomes, as well as uprooting and mechanical damage to plants; indirect effects include the dispersal of seeds either by endo- or epi-zoochory, changes in soil properties (Wirthner et al. 2012) as well as the alteration of plant-plant competitive mechanisms (Cushman et al. 2004).

Rooting is therefore expected to favour certain understorey species and disadvantage others, depending on plant ecological requirements and to those life-history traits related to the species' response to herbivory (hereafter intended in its broad sense including both above- and below-ground herbivory) and mechanical damage. For instance, the selective predation of large-seeded species may alter the composition of woody understorey, since in temperate forest systems large-seeded species are mainly trees and shrubs (Siemann et al. 2009). In the long-term, this selective predation may also favour certain tree species compared to others, and may affect the successional trajectory of the stand (Nuttle et al. 2014). Mechanical damage may instead favour clonal species, since clonality may allow a rapid recolonization of rooted patches (Catorci et al. 2012). This may lead to the development of a long-lasting layer of ferns or other browse-tolerant species that, in turn, may suppress or delay the recovery of other species after the cessation of the disturbance (Royo and Carson 2006, Nuttle et al. 2014).

Despite the specific mechanisms that rooting exerts on understorey vegetation, to the best of our knowledge, no study has yet directly focused on the life-history and ecological traits of vascular plants in relation to rooting. The goal of our study is to investigate the impact of contrasting levels of wild boar rooting on understorey vegetation, with particular reference to its composition, diversity and functional traits. Especially, we focused on response traits (i.e., those traits that determine how a species responds to a disturbance or environmental change), since these allow to draw general conclusions on how ground-layer plant communities are affected by rooting (Lavorel et al. 2007). We conducted a comparative analysis of plant communities in areas with contrasting levels of rooting intensity with the aim of understanding: i) whether rooting intensity influences understorey species composition and diversity; ii) which functional traits are associated with different levels of rooting.

Our working hypothesis is that rooting acts as an environmental filter that substantially alters understorey composition. We expected that a high level of rooting favoured species that are able either to avoid or tolerate rooting disturbance or to regenerate after rooting (Lavorel and Garnier 2002).
Indeed, we expected that an environmental change, such as an increased rooting pressure, may cause a shift in species composition both due to the response of the species initially occurring in the community, and to the replacement of those species not suited to the new conditions (see 'response rules' in Keddy 1992).

When compared to low rooting areas, in high rooting areas we expected to observe a higher proportion of i) species with a low specific leaf area (SLA), and ii) spinescent species, since these traits indicate the amount of investments in 'defence' against herbivory. In high rooting areas, we also expected a greater share of clonal species, since these may respond rapidly to disturbance, and of both epi- and endozoochorous species, which may be actively dispersed by wild boar. Finally, we hypothesized that these alterations result in significantly different levels of overall understorey species diversity, with lower species richness, diversity and evenness expected in high-rooting plots.

\section{Materials and methods}

\section{Study area}

The study was carried out in the Circeo National Park (Central Italy). This area is characterised by a Mediterranean oceanic bioclimate (Blasi et al. 2014), average annual temperature calculated on a monthly basis for the period 20042013 was $15.9^{\circ} \mathrm{C}$ with yearly average minimum and maximum temperatures of respectively 9.6 and $22.9^{\circ} \mathrm{C}$; annual rainfall was $808 \mathrm{~mm}$ (source: Pontinia meteorological station, $\sim 6 \mathrm{~km}$ apart from the study area; www.arsial.it/portalearsial/ agrometeo).

The National Park covers an area of about 5,600 ha and hosts several different habitats of high conservation concern. It includes a lowland forest that lies on a series of slightly undulating late-Pleistocene dunes comprised between 10 and $34 \mathrm{~m}$ a.s.1., and covers an area of about 3,200 ha. In relation to its morphological heterogeneity, the lowland forest hosts different vegetation types (Blasi et al. 2002): the depressions are often filled with water and host hygrophylic woods that are dominated by Quercus robur and Fraxinus angustifolia oxycarpa, whereas the higher-lying areas contain deciduous oak woods dominated by Quercus cerris and Quercus frainetto.

The density of wild boar in the lowland forest has fluctuated considerably since the 1930s. The species was reported to be locally extinct in 1938 , during vast drainage operations. Its reintroduction in the immediately subsequent years was followed by a rapid population increase (i.e., 100-200 individuals in the lowland forest). In the late $1950 \mathrm{~s}$, the population once again collapsed owing to the spread of swine fever. Since then the population recovered, and has grown steadily until present times despite several capture plans. According to a conservative estimation based on the number of boars encountered or trapped by the personnel of the State Forestry Corps working in the National Park, in 2004 the number of individuals was between 600 and 700 (Zerunian 2005). The intensity of rooting activity in the lowland forest has probably 
never been as high as it is currently for a series of directly and indirectly related events: the widespread land conversion to agriculture following the drainage, the consequent isolation of the forest, the local extinction of wild boar natural predators, and the establishment of the National Park within which hunting is forbidden (1934). Since then, the direct human disturbance within the lowland forest has been limited to paths and roads and their immediate surroundings. Domestic livestock is excluded from the whole lowland forest area. Another wild herbivore occurring in the area is the fallow deer Dama dama (L.), that is confined to a single forest stand (about 650 ha) in the south-eastern part of the forest, i.e., out of the forest sector that we sampled in this research.

\section{Rooting data collection and sampling design}

In order to reduce the background noise due to differences in environmental conditions, we focused on a single forest type. We chose the plant communitydominated by Quercus cerris and Quercus frainetto since this is the most widespread forest type of Circeo lowland forest. This strategy maximized the possibility for setting up our sampling design. The portion of the Circeo forest occupied by this forest type (Fig. 1) was surveyed for rooting activity during March-April 2010 in 14 randomly located rectangular areas sized 15 ha (210 ha in total). We designed the sampling of rooting intensity on the basis of the specific requirements of our study, i.e.,

\section{Circeo National Park} Lowland forest

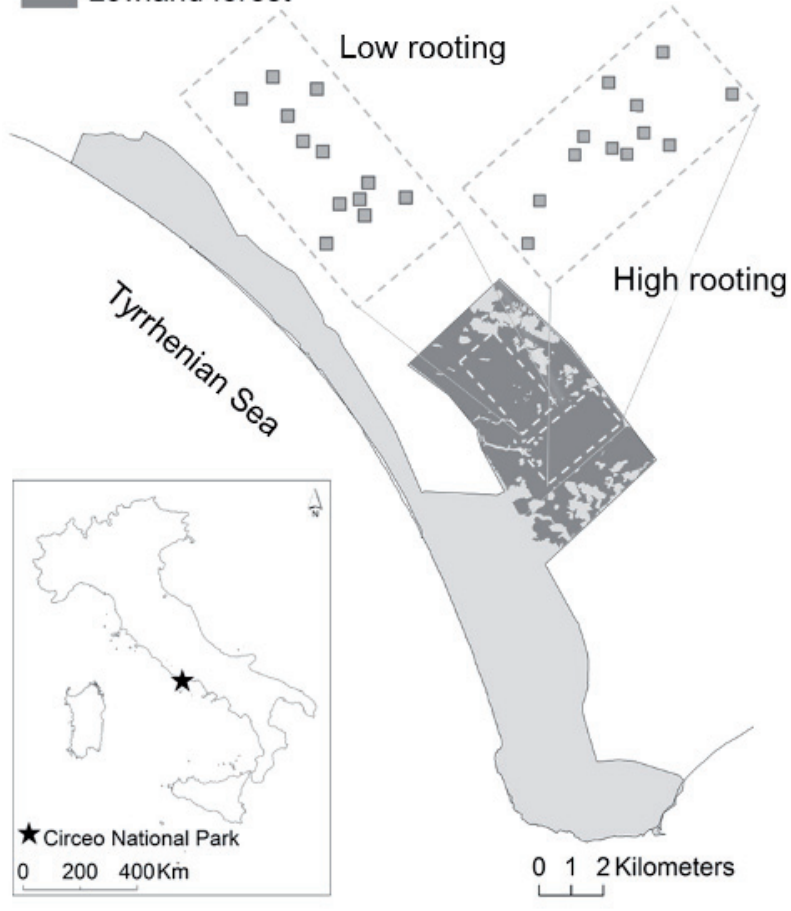

Figure 1. Study area: location in Italy of the Circeo National Park, distribution of the areas with high and low rooting intensity, and of the sampling units within the lowland forest. the need of a cost-efficient estimate of the degree and spread of rooting disturbance through the lowland forest. We measured rooting activity through counts of single rooting signs, defined as an approximately $15 \mathrm{~cm}$-wide sign of disturbed ground. Wider signs were evaluated as multiples of a single sign (e.g., a $30 \mathrm{~cm}$-wide sign $=2$ rooting-signs). Such counting represents a snapshot measure of the area subjected to wild boar disturbance, since detailed long-term data on rooting distribution was not available. Our method (discussed in detail in Fagiani et al. 2014) is very similar to the method adopted by Haaverstad et al. (2014), compared to which our transects were shorter $(100 \mathrm{~m}$ long instead of $1 \mathrm{~km})$ in relation to the smaller size of our sampling area, and narrower (5 meters wide instead of 10) since the dense understorey limited the possibility of confidently detecting rooting signs in a 10-meter wide area.

Since no part of the studied forest or of other similar forests within the region (Burrascano et al. 2015) resulted unaffected by rooting, instead of comparing rooted and unrooted areas, we had no alternative than comparing sites with contrasting levels of rooting intensity and analysing the response of vegetation to different levels of disturbance intensity, following the approach of other recent studies (Ma et al. 2013, Catorci et al. 2014).

The subsequent field sampling was conducted in two sectors of the forest: the northern sector displaying the lowest rooting intensity (hereafter low rooting), and the southern sector, where the highest rooting level occurred (hereafter high rooting). Such sectors are wider (approximately $2 \mathrm{~km}^{2}$ ) than the size of the core area of wild boar home range that was measured for central Italy (Boitani et al. 1994).

We sampled understorey composition and overstorey structure in 12 randomly located square plots for each rooting level (24 in total, Fig. 1). Each plot was $400 \mathrm{~m}^{2}$ in size. Furthermore, six soil samples were collected for each rooting level (12 in total). The same field crew surveyed all the vegetation plots (E. Giarrizzo, E. Del Vico and S. Burrascano).

\section{Overstorey structure and soil}

We sampled overstorey structure since it exerts an influence on the composition, diversity and spatial pattern of ground-layer plants (Burrascano et al. 2011, Sabatini et al. 2014a), and on the functional traits of the herb layer (Sabatini et al. 2014b). We sampled overstorey structure through a variable radius plot, using a wedge prism, centered on the $400 \mathrm{~m}^{2}$ plots used for the vegetation sampling (Avery and Burkhart 2002). We recorded the species, the diameter at breast height (DBH) and the vitality class (1, living; 2, living with dead parts; 3 , standing dead; 4 , broken above $1.3 \mathrm{~m}$ ) of all the standing live and dead trees included in the variable radius plot. We also recorded the mid-diameter, length and decay class (based on a five-grade scale, Hunter 1990) of every piece of lying deadwood with a diameter $>10 \mathrm{~cm}$ in the $400 \mathrm{~m}^{2}$ plot. We subsequently calculated, and included in the analysis, seven indicators of structural heterogeneity of mature and over-mature forests (Višnjić et al. 2013): number of 
stocked 5-cm diameter classes; number of standing trees with $\mathrm{DBH}>40 \mathrm{~cm}$; diameter range; the proportion of standing dead trees; coarse woody debris volume; number of decomposition classes; basal area.

Soil in the Circeo lowland forest is sandy regosol with limited water holding capacity (Dowgiallo and Bottini 1998). Soil samples were collected from the first $20 \mathrm{~cm}$ of soil, excluding litter. For each sample, we measured: $\mathrm{pH}$ (1:2.5 soil/ water suspension), organic matter fraction, organic $\mathrm{C}$ fraction (Walkley and Black method), $\mathrm{N}$ fraction (Kjeldahl method), C:N ratio and granulometry (Hydrometer method). The chemical and physical analyses were carried out according to the methods described in Van Reeuwijk (2002). To make sure the low- and the high-rooting areas were comparable in terms of soil features and overstorey structure, we tested for similar forest structure and soil conditions across rooting levels through the non-parametric Mann-Whitney U test (Table $\mathrm{S} 1$ in Appendix).

\section{Vegetation sampling and trait collection}

Each $400 \mathrm{~m}^{2}$ plot was divided in four $100 \mathrm{~m}^{2}$ subplots, within which we recorded the occurrence and the percentage cover value of each vascular plant taxon in May-June 2010; we averaged species cover values among subplots.

We collected data on nine functional traits for each species of the understorey that had a percentage cover greater than, or equal to, $1 \%$ in at least one sampling plot (38 species in total). We defined understorey species as herbs and shrubs less than $3.5 \mathrm{~m}$ high. We chose a set of functional traits (Table 2) that are particularly effective in the analysis of response to disturbance (Lavorel et al. 2007). We measured in the field or laboratory five traits according to Cornelissen et al. (2003): height, specific leaf area (SLA), spinescence, dispersule shape and dispersule size. Life form, growth form, clonality (i.e., the ability to reproduce vegetatively) and dispersal mode were derived either from online databases (CLO-PLA - Klimesova and de Bello 2009; LEDA - Kleyer et al. 2008) or from the literature (Pignatti 1982). The traits measured in this study (see Tab. S2 in Appendix) are available in the TRY database (Kattge et al. 2011).

\section{Data analysis - Diversity and composition}

We calculated species diversity indices (species richness, Shannon diversity and Pielou's evenness), and compared them between high- and low-rooting plots testing the differences for significance by means of the Mann-WhitneyWilcoxon non-parametric test.

The differences in understorey composition between high- and low-rooting plots were tested for significance through a permutational multivariate extension of the traditional analysis of variance (PERMANOVA - Anderson 2001) based on a pairwise plot-to-plot dissimilarity matrix calculated upon the Bray-Curtis dissimilarity coefficient for species abundances (i.e., cover values). Significance was tested through Monte-Carlo test (9999 permutations). We per- formed a Principal Coordinates Analysis (PCoA) using the Bray-Curtis coefficient to visualize and compare the results yielded by PERMANOVA.

Indicator values of all the vascular plant species for areas with high- and low-rooting intensities were calculated by means of the Indicator Species Analysis (ISA - Dufrêne and Legendre 1997) with 9999 permutations.

\section{Data analysis - Functional traits}

To examine the associations between traits and rooting intensity, we used the fourth-corner method (Dray and Legendre 2008). This method analyses the relationships between species traits and environmental variables through the link of three data matrices: species abundances at each site ( 38 species $\times 24$ sites), measurements of environmental variables at each site $(24$ sites $\times 2$ nominal states: high rooting, low rooting), and trait values for each species ( 38 species $\times 9$ traits). Since plant functional traits are often summarized by a mix of nominal and quantitative variables, the fourth-corner method uses the $\chi^{2}$ statistics for nominal variables, and the $F$ statistics for the quantitative ones (either ordinal or continuous).

We ran the test twice, using species cover and the presence/absence values in the species-by-site matrix separately. The significance levels of the fourth-corner statistics were obtained by permuting the values within each row vector of the species-by-site matrix at random 999 times.

Finally, we explored the correlation structure between functional traits by producing a PCoA biplot. This ordination was based on Gower dissimilarity measure, since this measure is appropriate when the dataset is a combination of quantitative, ordinal, nominal and binary variables.

All the analyses were performed in $\mathrm{R}$ (version 3.1.0; $\mathrm{R}$ Development Core Team 2014), using the function "Adonis" in the package "vegan" (version 2.0-10) for the PERMANOVA, the function "indval" in the package "labspdv" (version 1.6-1) for the ISA, and the function "fourthcorner" in the "ade4" package (Dray and Dufour 2007) for the fourth-corner analysis.

\section{Results}

\section{Diversity and composition}

Across the two treatments (i.e., high and low rooting) we found 100 species in total. The number of species found in high-rooting plots was 85 , while in low-rooting plots we found a total of 80 species. The median number of species per plot in high- and low-rooting areas was 27 and 31, respectively.

The comparison of the diversity indices showed that the main differences between rooting levels were related to shifts in dominance rather than to different species richness values. Indeed, species richness was not significantly different in high- vs. low-rooting areas (Mann-Whitney-Wilcoxon 
Table 1. Indicator species for high- and low-rooting areas. The p-values were obtained through 9999 permutations.

\begin{tabular}{lccc}
\hline Species & $\begin{array}{l}\text { Rooting } \\
\text { intensity }\end{array}$ & Ind. Value & p-value \\
\hline Ruscus aculeatus & Low & 89.4 & $<0.001$ \\
Asphodelus ramosus & Low & 78.5 & $<0.001$ \\
Lonicera etrusca & Low & 71.1 & 0.031 \\
Holcus lanatus & Low & 41.7 & 0.038 \\
Daphne laureola & Low & 41.7 & 0.038 \\
Phillyrea latifolia & High & 58.3 & 0.005 \\
Pteridium aquilinum & High & 65 & 0.002 \\
\hline
\end{tabular}

$W=58.5, p=0.452$ ), whereas evenness and Shannon diversity indices were significantly higher in high-rooting areas. The median of Shannon diversity was 1.31 in low-rooting and 1.93 in high rooting $(W=119, p=0.006)$. Evenness was significantly different between low- and high-rooting plots ( $W=129$, $p<0.001)$; the median values were 0.40 and 0.59 respectively. The lower diversity that characterises the low-rooting areas was likely related to the marked dominance of Ruscus aculeatus.

Through the use of PERMANOVA, we detected a significant difference in understorey composition between the different levels of rooting ( $p$ seudo- $F=14.703, p=0.001$ ). The first axis of the PCoA explained $46.2 \%$ of the variation in species composition, and clearly separated plots characterised by different levels of rooting intensity (Fig. 2). The second PCoA axis accounted for $17.2 \%$ of the variation, and did not segregate clearly the high- and low-rooting plots.
The ISA revealed five indicator species for the low-rooting areas and two for the high-rooting areas (Table 1). The species with the highest indicator value in the low-rooting areas was Ruscus aculeatus, which yielded very high cover values in the majority of the plots. Other species that were significantly more frequent in low-rooting areas were typical either of deciduous forests (Lonicera etrusca, Daphne laureola) or of open and disturbed habitats (Asphodelus ramosus, Holcus lanatus). The two indicator species identified in the high-rooting areas were a Mediterranean shrub (Phillyrea latifolia) and a cosmopolite clonal fern (Pteridium aquilinum).

A few species, which did not result as indicator species due to their low frequency values, were exclusive either of high- or of low-rooting areas. The most common species that we found exclusively in high-rooting areas were Brachypodium rupestre, Erica arborea and Phillyrea latifolia; while the most common species found exclusively in lowrooting plots were Allium triquetrum, Ranunculus ficaria, Cistus salvifolius and Stellaria media.

\section{Functional traits}

The fourth-corner analysis based on species cover values revealed that all the functional traits were significantly associated with rooting intensity, with low-rooting areas strongly dominated by thorny species with rhizomes and large edible dispersules (Table 2). On the other hand, we observed that height, SLA and elongated shaped dispersule were positively associated with high levels of rooting.

On the basis of species occurrences alone, high-rooting levels were positively associated with tussocks (cespitose
Figure 2. Scatter diagram based on Bray-Curtis plot-to-plot dissimilarity coefficients calculated from species cover values. Gray triangles represent low-rooting plots, black circles represent high-rooting plots.
PCoA (Bray-Curtis)

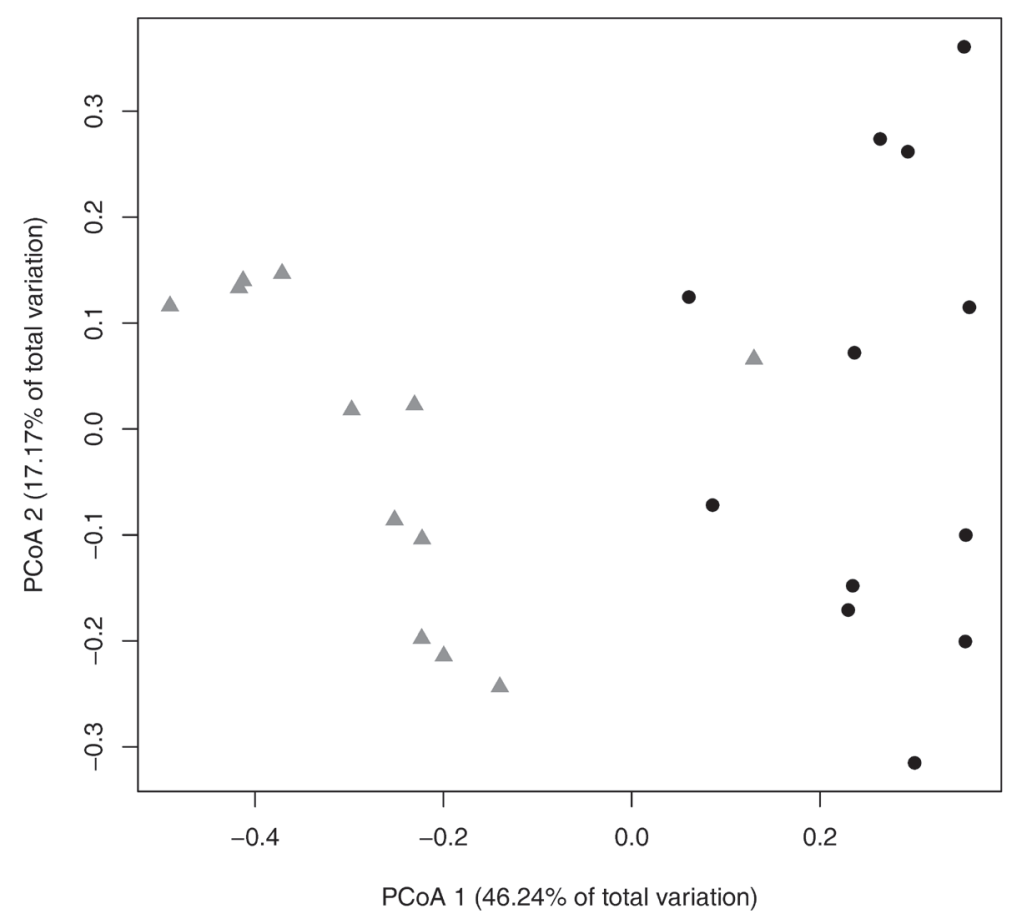


Table 2. Results of the fourth-corner analysis. We report the value of the statistics that was used for each trait $\left(\chi^{2}\right.$ for binary and nominal variables, F for quantitative and ordinal variables). We also report the sign (+/-) and p-value of the association with rooting levels for i) each trait (binary, ordinal and quantitative variables), and ii) each categorical state (nominal variables). All statistics were calculated both on the species cover and presence/absence (p/a) data. Significant association with rooting levels were obtained by permuting the values within each row vector of the species-by-site matrix at random 999 times. $†$ Data derived from Klimesova and de Bello (2009). $\$$ Data derived from Pignatti (1982). The other functional traits were measured in this work according to the guidelines reported in Cornelissen et al. (2003).

\begin{tabular}{|c|c|c|c|c|c|c|c|c|c|}
\hline \multirow{2}{*}{ Traits } & \multirow{2}{*}{ Variable type } & \multirow{2}{*}{ d.f. } & $\begin{array}{l}\text { species } \\
\text { cover }\end{array}$ & species $\mathrm{p} / \mathrm{a}$ & \multirow[b]{2}{*}{ Trait categories } & \multicolumn{2}{|c|}{ species cover } & \multicolumn{2}{|c|}{ species p/a } \\
\hline & & & \multicolumn{2}{|c|}{ Test statistics } & & $+/-$ & p-adj & $+/-$ & p-adj \\
\hline Clonality $\dagger$ & Binary & 35 & $\chi^{2}=46.8$ & $\chi^{2}=1.351$ & & - & 0.004 & - & 0.027 \\
\hline Spinescenceț & Ordinal & 37 & $F=255.6$ & $\mathrm{~F}=0.0003$ & & - & 0.002 & & n.s. \\
\hline Dispersule shape & Continuous & 25 & $\mathrm{~F}=135.8$ & $\mathrm{~F}=0.0000$ & & + & 0.002 & & n.s. \\
\hline Dispersule size (mm) & Continuous & 27 & $F=292.6$ & $\mathrm{~F}=0.196$ & & - & 0.002 & & n.s. \\
\hline Height $(\mathrm{cm}) \ddagger$ & Continuous & 34 & $F=30.3$ & $\mathrm{~F}=0.998$ & & + & 0.013 & + & 0.077 \\
\hline $\mathrm{SLA}\left(\mathrm{mm}^{2} / \mathrm{mg}\right)$ & Continuous & 33 & $\mathrm{~F}=38.8$ & $\mathrm{~F}=2.750$ & & + & 0.004 & - & 0.042 \\
\hline \multirow[t]{5}{*}{ Dispersal mode $\dagger$} & Nominal & 37 & $\chi^{2}=39.5$ & $\chi^{2}=0.864$ & Anemochorous & & n.s. & & n.s. \\
\hline & & & & & Ballistichorous & & n.s. & & n.s. \\
\hline & & & & & Endozoochory & - & 0.001 & & n.s. \\
\hline & & & & & Myrmecochory & & n.s. & & n.s. \\
\hline & & & & & Not specialized & & n.s. & & n.s. \\
\hline \multirow[t]{4}{*}{ Life Form } & Nominal & 37 & $\chi^{2}=221.4$ & $\chi^{2}=3.4$ & Geophytes & - & 0.008 & & n.s. \\
\hline & & & & & Hemicryptophytes & & n.s. & & n.s. \\
\hline & & & & & Phanerophytes & & n.s. & & n.s. \\
\hline & & & & & Therophytes & & n.s. & & n.s. \\
\hline \multirow[t]{8}{*}{ Growth Form } & Nominal & 37 & $\chi^{2}=230.5$ & $\chi^{2}=6.2$ & Bulbous & & n.s. & & n.s. \\
\hline & & & & & Cespitose & & n.s. & + & 0.032 \\
\hline & & & & & Vines & & n.s. & & n.s. \\
\hline & & & & & Nanophanerophytes & & n.s. & & n.s. \\
\hline & & & & & Reptant & & n.s. & & n.s. \\
\hline & & & & & Rhizomatous & - & 0.016 & & n.s. \\
\hline & & & & & Rosulate & & n.s. & & n.s. \\
\hline & & & & & Scapose & & n.s. & & n.s. \\
\hline
\end{tabular}

species) and negatively associated with clonality and SLA. The results obtained for SLA from presence-absence data are thus in contrast with those based on species cover. It is also interesting to note that the fourth-corner analysis based on species abundances resulted in a higher number of significant associations between rooting intensity and functional traits and their categories, compared with results from presence/ absence data.

Through the PCoA ordination of species life/history traits (Fig. S3 in Appendix), we noted some broad correlations between functional traits, and identified two main gradients of variation. The first gradient segregated thorny species with heavy, rounded dispersule and low SLA (Fig. S3), from species having high SLA, elongated, light dispersules and no thorns. The former group was mainly composed of shrubs and vines such as Rubus sp.pl., Smilax aspera, Ruscus aculeatus, while the latter group was characterized by graminoids such as Poa sylvicola, Carex distachya, Brachypodium sylvaticum and other hemicryptophytes, e.g., Ranunculus velutinus, Teucrium siculum. The second main gradient was principally related to plant height and clearly separated cespitose phan- erophytes and nanophanerophytes from the other growth forms (especially rhizomatous geophytes, top left). The first two axes of the PCoA ordination explained respectively 36.4 and $23.2 \%$ of the variation.

\section{Discussion}

Rooting causes shifts in understorey dominance through uneven impacts on species with different functional traits

Our results showed that different rooting levels were not associated with shifts in species richness as it was found also in other studies focused on understorey (Bratton 1975). However, we observed great differences in understorey species composition and dominance in relation to rooting levels. Indeed, when mediated by species abundance values, all traits resulted as significantly related to rooting intensity, whereas the same was not true when presence/absence data were used. Such shifts in dominance may derive from two different mechanisms: on the one hand the foraging behav- 
iour of wild boar may be extremely selective (Sandom et al. 2013), and can lead to the substantial decrease of a few species especially in certain seasons and conditions (Ballari and Barrios-Garcia 2014); on the other hand, wild boar rooting produces disturbed areas that are prone to the colonization by few species able to reproduce vegetatively as it was observed in Gray Beech Forest of the Great Smoky Mountains (Bratton 1975). Interestingly, both these mechanisms strongly depend on understorey species functional traits, the first depending on palatability, the second being influenced by species ability to reproduce vegetatively.

Our analysis of individual functional traits suggested the existence of a complex relationship between wild boar activities and understorey compositional changes, with rooting intensity displaying a certain degree of association with all functional traits, including those related to palatability and vegetative reproduction.

Spinescence was significantly related to rooting level, in agreement with previous findings that thorny species limits wild boar rooting activity in Mediterranean forest (Perea and Gil 2014). This association strongly emerges from our data since, within the lowland forest, thorny species very often composed widespread, dense thickets, e.g., in 8 out of the 24 plots we sampled, thorny plants covered more than $50 \%$ of the ground.

Also low SLA may be deemed as an indicator of leaf defence against herbivory, since it is the result of high investments in leaf structures (Wright et al. 2004). Contrary to our expectations, when we analysed species cover values we observed a positive association between SLA and rooting intensity that was mainly due to the marked dominance in the low-rooting plots of a single species with low SLA values (i.e., Ruscus aculeatus). Conversely, a negative association emerged when we considered presence/absence data, as most of the species with the highest SLA values were absent in high-rooting plots (e.g., Allium triquetrum, Stellaria media, Ranunculus ficaria). Among these species, Allium triquetrum and Ranunculus ficaria are vernal geophytes, a functional group typical of deciduous forests. These plants are characterised by a high SLA owing to their need to attain high photosynthetic rates to effectively take advantage of the enhanced amount of light reaching the forest floor prior to the leafing of the overstorey (Wright et al. 2004, Sabatini et al. 2014b). Although no facilitative role of Ruscus aculeatus was demonstrated so far (Brooker et al. 2008), these vernal geophytes have low dispersal ability, and are likely to be facilitated by a dense Ruscus aculeatus thicket, which may provide protection from the direct predation by the wild boar (Cuevas et al. 2010, Perea and Gil 2014).

Finally, clonality allows a quick vegetative colonization that is especially effective when disturbance operates at very small scales, such as in the studied forest (Catorci et al. 2012), where the great majority of the rooted patches had a size between 0.02 and $0.5 \mathrm{~m}^{2}$. A more detailed analysis of spatial patterns of rooting activities (e.g., such as the size and configuration of rooting patches, see Welander 2000) would have allowed to more detailed conclusions with respect to some key traits (e.g., clonality). However, here we focused on stand-scale vegetation dynamics and such a fine-scale analysis was beyond the scope of the present study.

\section{Long-term biological legacies may explain the observed interactions between wild boar and understorey}

Part of our results were unexpected: according to our original hypothesis, we expected that high levels of rooting were associated with species that are adapted to rooting disturbance through mechanisms such as avoidance, tolerance or rapid regeneration. We also expected a negative impact of rooting on those species upon which wild boar directly feed. However, the fourth-corner analysis did not confirm our hypotheses, as demonstrated by the negative association that emerged between the high-rooting sites and i) spinescence, ii) clonality and iii) endozoochory.

Furthermore, low-rooting areas were characterised by the occurrence of indicator species that are typically related to frequently disturbed areas, such as Asphodelus ramosus and Holcus lanatus and whose occurrences in the lowland forest cannot be related to other types of disturbance than wild boar rooting, neither fire, nor grazing by domestic livestock nor direct human influence. Other species found exclusively, or more frequently, in the low-rooting areas were Stellaria media and Rumex acetosa, i.e., species that are known to take great advantage of wild boar for their dispersal through endozoochory and epizoochory respectively (Schmidt et al. 2004, Heinken et al. 2006). The fact that bracken (Pteridium aquilinum) was an indicator of high rooting, while it was absent in low rooting plots, was also unexpected. Bracken rhizomes are consumed by wild boar and, in a Scottish forest lacking mast species, Sandom et al. (2013) report that bracken-dominated understories are severely impacted by wild boar rooting.

Altogether, these results may be interpreted assuming the existence of long-term biological legacies of wild boar rooting in the understorey: instead of a synchronic cause-effect relationship, the interaction between wild boar and understorey vegetation is mediated by changes in the functional response traits of the herb-layer, which 'store' information about the past disturbance history of a stand (Paušič and Čarni 2013).

We hypothesise that the northern part of the forest, where the low rooting areas are located, was the first area to be subjected to an intense use by wild boar after the recent increase of its population. Such an intense rooting disturbance that happened in the near-past is likely to have had important biological legacies on current understorey communities. The most noticeable legacy was the establishment of a dense layer of Ruscus aculeatus and this had long-lasting consequences on the diversity and evenness of the undestorey. Following the spread of Ruscus aculeatus, the understorey became hardly suitable for further use by wild boar, whose impact likely expanded progressively to previously undisturbed or less disturbed parts of the forest, i.e., those that now display a high rooting level.

Our hypothesis is supported both by past vegetation data and by a series of considerations on the sector where the low- 
rooting sites are located. Vegetation relevés, performed about 15 years ago in the same part of the forest where our low rooting sampling plots were located, report cover values for Ruscus aculeatus well below those that we observed (Blasi et al. 2002). Furthermore, although we excluded from sampling both the topographic depressions and the surrounding hygrophilic vegetation, the northern part of the forest is characterized by numerous pools and temporary ponds, and by a relatively low use of paths and roads by humans. Therefore, after the recent demographic explosion it is likely that the northern sector of the lowland forest was the first area of the forest to be intensely used by wild boar: i) for feeding purposes, since wild boar are known to preferentially feed in moister areas (Hone 2002, Li et al. 2013); ii) for wallowing; iii) as a refuge from indirect human disturbance (see Ohashi et al. 2013).

In this context, we think that the spread and persistence of Ruscus aculeatus may derive by its functional characteristics, especially related to its: i) low palatability, and ii) very high resprouting ability. As a matter of fact, this species does not represent a relevant source of food for wild boar and other herbivores since, due to its spinescence, only very young shoots (i.e., those shoots within a month from their development) may be consumed by herbivores. Moreover, Ruscus aculeatus rapidly resprouts after predation or mechanical damage, and this capability allows a very rapid recovery after grazing (Martinez-Palle and Aronne 1999). Indeed, this species was already observed to be more abundant in grazed when compared to ungrazed forests (Onaindia et al. 2004) and to persist for more than 10 years after the cessation of grazing (Debussche et al. 2001). Once it is established, Ruscus aculeatus forms dense long-lasting thickets that likely hamper wild boar from rooting wide patches of the forest floor (Haaverstad et al. 2014).

These observations closely match the 'response rules', according to which a change in the environment (i.e., the rapid increase in wild boar rooting activities over the last 50 years) eliminates those species lacking specific trait combinations, and favours the colonization by species with traits suitable to the new conditions (Keddy 1992).

The legacy effect we hypothesize is similar to that caused by the intense deer browsing in northern hardwood forests. In that system deer overbrowsing resulted in the formation of a long-lasting (recalcitrant sensu Royo and Carson 2006) herb-layer dominated by unpalatable ferns, that lasted more than 20 years even after a substantial decrease in deer density (Nuttle et al. 2014). The existence of this legacy effect points to the limits of a synchronic approach for the study of wild boar impact on understorey. Therefore, we suggest that future studies attempt to measure rooting activities over longer time-periods than we did given the high varibility of rooting activity in space and time (Welander 2000).

\section{Conclusions}

This study shows that wild boar rooting activity alters understorey composition causing modifications in species dominance through the selective predation or avoidance of species with different functional traits. The association between rooting levels and functional traits we observed likely derive from the long-term legacy effects of previous intense rooting, rather than on current rooting disturbance.

We hypothesized a complex set of interactions between wild boar rooting and understorey species that include both an important impact of wild boar rooting on the herb-layer as well as a consequent effect of understorey composition on wild boar feeding behaviour. Indeed, the drastic recent increase in the density of wild boar likely caused severe shifts in understorey composition that in turn hampered the ability of wild boar to feed in the previously impacted areas, i.e., the areas in which we measured low rooting intensity are those in which such activity is limited by the occurrence of a dense thicket of Ruscus aculeatus.

However, this sequence of environmental changes is probably not cyclic, since the areas occupied by the dense thickets of Ruscus aculeatus may remain unsuitable to wild boar for years, thus influencing the spatial arrangement of further feeding activities for a long period. Based on our results and on previous scientific literature (Nuttle et al. 2014), forest managers aiming at restoring a diverse herbaceous community should be aware that the thickets of Ruscus aculeatus probably attained such strong dominance due to intense rooting disturbance and that this dominance may last for decades. Managers should thus consider the idea of implementing Ruscus aculeatus eradication measures in combination with effective measures of wild boar population control (enhanced trapping or exclosures). In small isolated forests, as the one we studied, this combination of management actions may be useful to avoid an increasing forest area to become unsuitable to wild boar feeding activities and therefore to avoid a progressively increasing rooting disturbance to the remaining forest area and/or increasing damages to the surrounding agricultural areas.

Acknowledgements. This work was supported by the National Park of Circeo. Our thanks go to G. Tallone, D. Capizzi and A. Monaco and to the staff of the State Forestry Corps for help during the project. We wish to thank G. Dowgiallo for her assistance in the analysis of the soils, and L. Baker for editing the English in the manuscript.

\section{References}

Abbate, G., S. Bonacquisti, S. Burrascano, E. Giovi, A. Giuliani, F. Pretto and E. Scassellati. 2015. Woody flora as a predictor of vascular plant richness: An insight in Italy. Plant Biosyst. 149: 565-573.

Anderson, M.J. 2001. A new method for non-parametric multivariate analysis of variance. Austral. Ecol. 26: 32-46.

Avery, E.T. and E.H. Burkhart. 2002. Forest Measurements. 5th ed. McGraw-Hill Higher Education, New York, NY.

Ballari, S.A. and M.N. Barrios-Garcia. 2014. A review of wild boar Sus scrofa diet and factors affecting food selection in native and introduced ranges. Mammal. Rev. 44: 124-134. 
Barrios-Garcia, M.N. and S.A. Ballari. 2012. Impact of wild boar (Sus scrofa) in its introduced and native range: a review. Biol. Invasions 14: 2283-2300.

Bieber, C. and T. Ruf. 2005. Population dynamics in wild boar Sus scrofa: ecology, elasticity of growth rate and implications for the management of pulsed resource consumers. J. Appl. Ecol. 42: 1203-1213.

Blasi, C., G. Capotorti, R. Copiz, D. Guida, B. Mollo, D. Smiraglia, and L. Zavattero. 2014. Classification and mapping of the ecoregions of Italy. Plant Biosyst. 148: 1255-1345.

Blasi, C., L. Filesi, A. Stanisci, R. Frondoni, R. Di Pietro, and M. L. Carranza. 2002. Excursion to the Circeo National Park. Fitosociologia 39: 91-130.

Boitani, L., L. Mattei, D. Nonis and F. Corsi. 1994. Spatial and activity patterns of wild boars in Tuscany, Italy. J. Mammal. 75: 600-612.

Bratton, S.P. 1975. The Effect of the European Wild Boar, Sus scrofa, on Gray Beech Forest in the Great Smoky Mountains. Ecology 56: 1356-1366.

Brooker, R.W., F.T. Maestre, R.M. Callaway, C.L. Lortie, L.A. Cavieres, G. Kunstler, P. Liancourt, K. Tielboerger, J.M.J. Travis, F. Anthelme, C. Armas, L. Coll, E. Corcket, S. Delzon, E. Forey, Z. Kikvidze, J. Olofsson, F.I. Pugnaire, C.L. Quiroz, P. Saccone, K. Schiffers, M. Seifan, B. Touzard and R. Michalet. 2008. Facilitation in plant communities: the past, the present, and the future. J. Ecol. 96: 18-34.

Burrascano, S., F.M. Sabatini and C. Blasi. 2011. Testing indicators of sustainable forest management on understorey composition and diversity in southern Italy through variation partitioning. Plant Ecol. 212: 829-841.

Burrascano, S., E. Giarrizzo, S. Bonacquisti, R. Copiz, E. Del Vico, S. Fagiani, A. Mortelliti and C. Blasi. 2015. Quantifying Sus scrofa rooting effects on the understorey of the deciduous broadleaf forests in Castelporziano Estate (Italy). Rendiconti Lincei. 26, Suppl. 3: 317-324.

Catorci, A., R. Gatti and S. Cesaretti. 2012. Effect of sheep and horse grazing on species and functional composition of sub-Mediterranean grasslands. Appl. Veg. Sci. 15: 459-469.

Catorci, A., S. Cesaretti and F.M. Tardella. 2014. Effect of tall-grass invasion on the flowering-related functional pattern of submediterranean hay-meadows. Plant Biosyst. 148: 1127-1137.

Champagnon, J., J. Elmberg, M. Guillemain, M. Gauthier-Clerc and J.D. Lebreton. 2012. Conspecifics can be aliens too: A review of effects of restocking practices in vertebrates. J. Nat. Conserv. 20: 231-241.

Conti, F., G. Abbate, A. Alessandrini and C. Blasi. 2005. An annotated checklist of Italian vascular flora, 1st edn. Palombi Editore, Roma.

Cornelissen, J.H.C., S. Lavorel, E. Garnier, S. Diaz, N. Buchmann, D.E. Gurvich, P.B. Reich, H. ter Steege, H.D. Morgan, M.G.A. van der Heijden, J.G. Pausas and H. Poorter. 2003. A handbook of protocols for standardised and easy measurement of plant functional traits worldwide. Aust. J. Bot. 51: 335-380.

Cuevas, M.F., A. Novillo, C. Campos, M.A. Dacar and R.A. Ojeda. 2010. Food habits and impact of rooting behaviour of the invasive wild boar, Sus scrofa, in a protected area of the Monte Desert, Argentina. J. Arid Environ. 74: 1582-1585.

Cushman, J.H., T.A. Tierney and J.M. Hinds. 2004. Variable effects of feral pig disturbances on native and exotic plants in a California grassland. Ecol. Appl. 14: 1746-1756.

Debussche, M., G. Debussche and J. Lepart. 2001. Changes in the vegetation of Quercus pubescens woodland after cessation of coppicing and grazing. J. Veg. Sci. 12: 81-92.
Dowgiallo, G. and D. Bottini. 1998. Aspetti pedologici del Parco Nazionale del Circeo. In: A. Stanisci and S. Zerunian (eds), Flora e Vegetazine del Parco Nazionale del Circeo. Ministero per le Politiche Agricole, gestione ex A.S.F.D., Sabaudia. pp. 33-46.

Dray, S. and A.B. Dufour. 2007. The ade4 package: implementing the duality diagram for ecologists. J. Stat. Softw. 22: 1-20.

Dray, S. and P. Legendre. 2008. Testing the species traits-environment relationships: the fourth-corner problem revisited. Ecology 89: 3400-3412.

Dufrêne, M. and P. Legendre. 1997. Species assemblages and indicator species: the need for a flexible asymmetrical approach. Ecol. Monogr. 61: 345-366.

Fagiani, S., D. Fipaldini, L. Santarelli, S. Burrascano, E. Del Vico, E. Giarrizzo, M. Mei, A.V. Taglianti, L. Boitani and A. Mortelliti. 2014. Monitoring protocols for the evaluation of the impact of wild boar (Sus scrofa) rooting on plants and animals in forest ecosystems. Hystrix 25: 31-38.

Gilliam, F.S. 2007. The ecological significance of the herbaceous layer in temperate forest ecosystems. Bioscience 57: 845-858.

Gomez, J.M. and J.A. Hodar. 2008. Wild boars (Sus scrofa) affect the recruitment rate and spatial distribution of holm oak (Quercus ilex). For. Ecol. Manag. 256: 1384-1389.

Haaverstad, O., O. Hjeljord and H.K. Wam. 2014. Wild boar rooting in a northern coniferous forest - minor silviculture impact. Scand. J. Forest Res. 29: 90-95.

Heinken, T., M. Schmidt, G. von Oheimb, W.U. Kriebitzsch and H. Ellenberg. 2006. Soil seed banks near rubbing trees indicate dispersal of plant species into forests by wild boar. Basic Appl. Ecol. 7: 31-44.

Hone, J. 2002. Feral pigs in Namadgi National Park, Australia: dynamics, impacts and management. Biol. Conserv. 105: 231-242.

Hunter, M.L. 1990. Wildlife, Forests and Forestry: Principles of Managing Forests for Biological Diversity. Prentice Hall, Englewood Cliffs.

Ickes, K., C.J. Paciorek and S.C. Thomas. 2005. Impacts of nest construction by native pigs (Sus scrofa) on lowland Malaysian rain forest saplings. Ecology 86: 1540-1547.

Kattge, J., S. Diaz, S. Lavorel, C. Prentice, P. Leadley et al. 2011. TRY - a global database of plant traits. Global Change Biol. 17: 2905-2935.

Keddy, P.A. 1992. Assembly and response rules - 2 goals for predictive community ecology. J. Veg. Sci. 3: 157-164.

Kleyer, M., R.M. Bekker, I.C. Knevel, J.P. Bakker, K. Thompson, M. Sonnenschein, P. Poschlod, J.M. van Groenendael, L. Klimes, J. Klimesova, S. Klotz, G.M. Rusch, M. Hermy, D. Adriaens, G. Boedeltje, B. Bossuyt, A. Dannemann, P. Endels, L. Gotzenberger, J.G. Hodgson, A.K. Jackel, I. Kuhn, D. Kunzmann, W.A. Ozinga, C. Romermann, M. Stadler, J. Schlegelmilch, H. J. Steendam, O. Tackenberg, B. Wilmann, J.H.C. Cornelissen, O. Eriksson, E. Garnier and B. Peco. 2008. The LEDA Traitbase: a database of life-history traits of the Northwest European flora. $J$. Ecol. 96: 1266-1274.

Klimesova, J. and F. de Bello. 2009. CLO-PLA: the database of clonal and bud bank traits of Central European flora. J. Veg. Sci. 20: 511-516.

Lavorel, S., S. Díaz, J.H.C. Cornelissen, E. Garnier, S.P. Harrison, S. McIntyre, J.G. Pausas, N. Pérez-Harguindeguy, C. Roumet and C. Urcelay. 2007. Plant Functional Types: Are We Getting Any Closer to the Holy Grail? In: J. Canadell, D. Pataki and L. Pitelka (eds), Terrestrial Ecosystems in a Changing World. Springer-Verlag, Berlin Heidelberg. pp. 149-164. 
Lavorel, S. and E. Garnier. 2002. Predicting changes in community composition and ecosystem functioning from plant traits: revisiting the Holy Grail. Funct. Ecol. 16: 545-556.

Li, L.L., J.B. Shi, J. Wang, Y.M. Gao, L.B. Wang, J.Q. Wang and X. Ying. 2013. Factors influencing wild boar damage in Taohongling National Nature Reserve in China: a model approach. Eur. J. Wildl. Res. 59: 179-184.

Ma, M., X. Zhou and G. Du. 2013. Effects of disturbance intensity on seasonal dynamics of alpine meadow soil seed banks on the Tibetan Plateau. Plant Soil 369: 283-295.

Martinez-Palle, E. and G. Aronne. 1999. Flower development and reproductive continuity in Mediterranean Ruscus aculeatus L. (Liliaceae). Protoplasma 208: 58-64.

Massei, G. and P. Genov. 2004. The environmental impact of wild boar. Galemys 16: 135-145.

Nuttle, T., T.E. Ristau and A.A. Royo. 2014. Long-term biological legacies of herbivore density in a landscape-scale experiment: forest understoreys reflect past deer density treatments for at least 20 years. J. Ecol. 102: 221-228.

Ohashi, H., M. Saito, R. Horie, H. Tsunoda, H. Noba, H. Ishii, T. Kuwabara, Y. Hiroshige, S. Koike, Y. Hoshino, H. Toda and K. Kaji. 2013. Differences in the activity pattern of the wild boar Sus scrofa related to human disturbance. Eur. J. Wildl. Res. 59: 167-177.

Onaindia, M., I. Dominguez, I. Albizu, C. Garbisu and I. Amezaga. 2004. Vegetation diversity and vertical structure as indicators of forest disturbance. For. Ecol. Manag. 195: 341-354.

Paušič, A. and A. Čarni. 2013. Records of past land use are best stored in soil properties. Plant Biosyst. 147: 654-663.

Perea, R. and L. Gil. 2014. Tree regeneration under high levels of wild ungulates: The use of chemically vs. physically-defended shrubs. For. Ecol. Manag. 312: 47-54.

Pignatti, S. 1982. Flora d'Italia. Edagricole, Bologna.

Pinna, W., G. Nieddu, G. Moniello and M.G. Cappai. 2007. Vegetable and animal food sorts found in the gastric content of Sardinian Wild Boar (Sus scrofa meridionalis). J. Anim. Physiol. Anim. Nutr. 91: 252-255.

Royo, A.A. and W.P. Carson. 2006. On the formation of dense understory layers in forests worldwide: consequences and implications for forest dynamics, biodiversity, and succession. Can. J. For. Res. 36: 1345-1362.

Sabatini, F.M., S. Burrascano, H. Tuomisto and C. Blasi. 2014a. Ground layer plant species turnover and beta diversity in Southern-European old-growth forests. PLOS ONE 9: e95244.

Sabatini, F.M., J.I. Burton, R.M. Scheller, K.L. Amatangelo and D.J. Mladenoff. 2014b. Functional diversity of ground-layer plant communities in old-growth and managed northern hardwood forests. Appl. Veg. Sci. 17: 398-407.

Saezroyuela, C. and J.L. Telleria. 1986. The increased population of the wild boar (Sus scrofa L.) in Europe. Mammal. Rev. 16: $97-$ 101.

Sandom, C.J., J. Hughes and D.W. Macdonald. 2013. Rewilding the Scottish Highlands: Do wild boar, Sus scrofa, use a suitable foraging strategy to be effective ecosystem engineers? Restor. Ecol. 21: $336-343$.

Schley, L., M. Dufrene, A. Krier and A.C. Frantz. 2008. Patterns of crop damage by wild boar (Sus scrofa) in Luxembourg over a 10-year period. Eur. J. Wildl. Res. 54: 589-599.
Schmidt, M., K. Sommer, W.U. Kriebitzsch, H. Ellenberg and G. von Oheimb. 2004. Dispersal of vascular plants by game in northern Germany. Part I: Roe deer (Capreolus capreolus) and wild boar (Sus scrofa). Eur. J. Forest Res. 123: 167-176.

Siemann, E., J.A. Carrillo, C.A. Gabler, R. Zipp and W.E. Rogers. 2009. Experimental test of the impacts of feral hogs on forest dynamics and processes in the southeastern US. For. Ecol. Manag. 258: 546-553.

Sims, N.K., E.A. John and A.J.A. Stewart. 2014. Short-term response and recovery of bluebells (Hyacinthoides non-scripta) after rooting by wild boar (Sus scrofa). Plant Ecol. 215: 1409-1416.

Valenzuela, A.E.J., C.B. Anderson, L. Fasola and J.L. Cabello. 2014. Linking invasive exotic vertebrates and their ecosystem impacts in Tierra del Fuego to test theory and determine action. Acta Oecol. 54: 110-118.

Van Reeuwijk, L.P. (ed.). 2002. Procedures for Soil Analysis, $6^{\text {th }}$ edition. Tech. Pap. 9, ISRIC. Wageningen.

Višnjić, Ć., S. Solaković, F. Mekić, B. Balić, S. Vojniković, M. Dautbašić, S. Gurda, F. Ioras, J. Ratnasingam and I.V. Abrudan. 2013. Comparison of structure, regeneration and dead wood in virgin forest remnant and managed forest on Grmeč Mountain in Western Bosnia. Plant Biosyst. 147: 913-922.

Welander, J. 2000. Spatial and temporal dynamics of wild boar (Sus scrofa) rooting in a mosaic landscape. J. Zool. 252: 263-271.

Wirthner, S., M. Schutz, D.S. Page-Dumroese, M.D. Busse, J.W. Kirchner and A.C. Risch. 2012. Do changes in soil properties after rooting by wild boars (Sus scrofa) affect understory vegetation in Swiss hardwood forests? Can. J. For. Res. 42: 585-592.

Wright, I.J., P.B. Reich, M. Westoby, D.D. Ackerly, Z. Baruch, F. Bongers, J. Cavender-Bares, T. Chapin, J.H.C. Cornelissen, M. Diemer, J. Flexas, E. Garnier, P.K. Groom, J. Gulias, K. Hikosaka, B.B. Lamont, T. Lee, W. Lee, C. Lusk, J.J. Midgley, M.L. Navas, U. Niinemets, J. Oleksyn, N. Osada, H. Poorter, P. Poot, L. Prior, V.I. Pyankov, C. Roumet, S.C. Thomas, M.G. Tjoelker, E.J. Veneklaas and R. Villar. 2004. The worldwide leaf economics spectrum. Nature 428: 821-827.

Zerunian S. 2005. Studio di fattibilità per la reintroduzione di specie significative e gestione sostenibile del cinghiale nel Parco Nazionale del Circeo, Contributo di Ricerca con atto del 02 Febbraio 2005. Parco Nazionale del Circeo. Received September 22, 2014
Revised June 28, 2014

Accepted March 25, 2015

\section{Electronic Appendix}

Table S1. Results relative to the analysis and comparison (Mann-Whitney $U$ and p-value) of the overstorey structure and soil between the high and the low rooting levels.

Table S2. Functional traits for the species of the understorey that had a percentage cover greater than, or equal to, $1 \%$ in at least one sampling plot.

Figure S3. Principal Coordinate Analysis of species lifehistory traits.

The file may be downloaded from www.akademiai.com. 